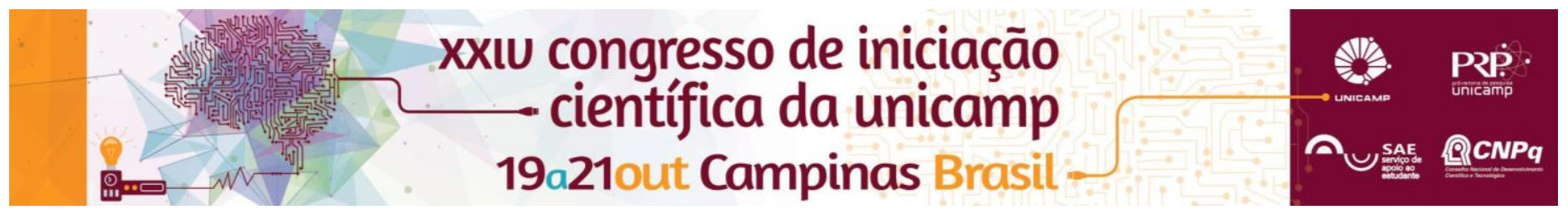

\title{
Triagem Neonatal para Colestase
}

\author{
Luciana Garcia Di Paolo*(IC), Gabriel Hessel(PQ), Rodrigo Ramos Catharino(PQ)
}

\section{Resumo}

A colestase é definida como redução ou ausência do fluxo biliar para o duodeno por alterações anatômicas e/ou funcionais, podendo ser dividida anatomicamente em intra-hepática e extra-hepática, sendo esta definida principalmente pela atresia biliar, que é a principal causa de colestase crônica da infância e a principal indicação de transplante hepático nesta faixa etária, se não diagnosticada e tratada adequadamente. $\mathrm{O}$ objetivo deste trabalho é a identificação de marcadores de colestase no exame de triagem neonatal para o encaminhamento precoce a centros referenciados para seguimento e tratamento adequados conforme a etiologia.

Palavras-chave: triagem, colestase, atresia biliar

\section{Introdução}

A colestase é definida como redução ou ausência do fluxo biliar para o duodeno por alterações anatômicas e/ou funcionais ${ }^{1}$, sendo verificada pela presença de icterícia, colúria, acolia ou hipocolia fecal e avaliada pela elevação de bilirrubina direta. Pode ser classificada anatomicamente em colestase intra-hepática $(\mathrm{ClH})$, cujas causas envolvem principalmente infecções congênitas e doenças metabólicas, e extra-hepática (CEH), sendo esta representada principalmente pela atresia biliar (AB). $A A B$ é a causa mais comum de colestase crônica na infância e a mais frequente indicação de transplante hepático nesse grupo etário. ${ }^{2} \mathrm{O}$ único tratamento disponível para a atresia biliar é a cirurgia de Kasai, que, se bem sucedida, aumenta a sobrevida das crianças em até $44 \%^{3}$. No Brasil, a maioria dos pacientes é submetida à cirurgia tardiamente, pois chegam a um serviço de referência por volta de 3 meses de idade ${ }^{4}$, sendo maior a necessidade de transplante hepático. O objetivo deste trabalho é identificar marcadores de colestase na triagem neonatal que auxiliem no diagnóstico e encaminhamento precoce dos pacientes a centros referenciados para tratatamento adequado conforme a etiologia.

\section{Resultados e Discussão}

Participaram do estudo 22 recém-nascidos, sendo que 8 desenvolveram colestase neonatal (grupo I) e 14 controles saudáveis (grupo II). Após aprovação pelo Comitê de Ética da FCM/UNICAMP e assinatura do consentimento informado, amostras foram obtidas originadas do Programa de Triagem Neonatal da UNICAMP. O sangue seco contido no papel filtro foi analisado por espectrometria de massas de alta resolução. A análise estatística demonstrou total separação entre os grupos I e II, e está descrita a seguir.

Figura 1. Análise discriminante de mínimos quadrados.
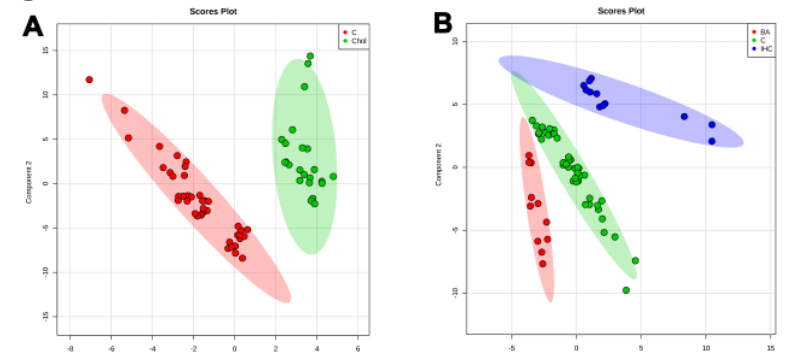

A figura A mostra a comparação entre o grupo I (Colestase) e o grupo II (Controle). A figura B mostra a comparação entre Colestase Intra-Hepatica, Atresia Biliar e Controles. Na comparação A, 7 biomarcadores foram selecionados para colestase e 4 biomarcadores para o grupo controle, com a curva ROC fornecendo $100 \%$ de sensibilidade e especificidade. $\mathrm{Na}$ comparação $\mathrm{B}, 4$ biomarcadores foram selecionados para discriminar atresia biliar de outras causas de colestase e a curva ROC forneceu $45 \%$ de sensibilidade e $74 \%$ de especificidade. (Figura 2)
Figura 2. Curvas ROC
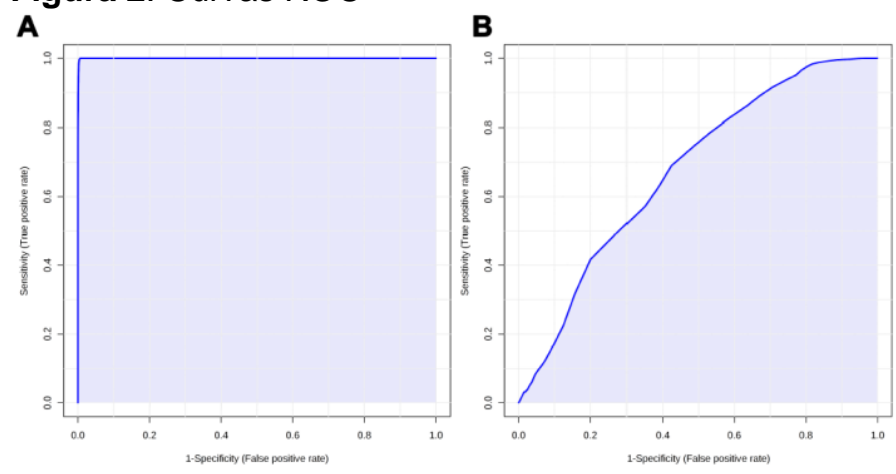

\section{Conclusões}

Houve identificação de biomarcadores de colestase neonatal em exame de triagem por meio de papel filtro e isso constitui um avanço na possibilidade de investigação precoce de doenças potencialmente fatais nessa faixa etária.

\section{Agradecimentos}

Ao CIPOI (Centro Integrado de pesquisas oncohematológicas na infância - FCM/UNICAMP) por fornecer o material dos sujeitos dessa pesquisa.

1. Poupon R, Chazouillères O, Poupon RE. Chronic cholestatic diseases. J Hepatol 2000; 32:129-40.

2. Hessel G, Sawamura R. Colestase do lactente. In: Morais MB. Gastroenterologia e Hepatologia na Prática Pediátrica. $2^{\mathrm{a}}$ ed. São Paulo: Atheneu, 2012. 139-52

3. Gallo A, Esquivel CO. Current options for management of biliary atresia. Pediatr Transplant. 2013 Mar;17(2):95-8.

4. Kieling CO, Santos JL, Vieira SM, Ferreira CT, Linhares AR, Lorentz AL, Silveira TR. Biliary atresia: We still operate too late. J Pediatr (Rio J) 2008; 84(5): 436-41 